\title{
Pharmacological characterisation of the interaction between glycopyrronium bromide and indacaterol fumarate in human isolated bronchi, small airways and bronchial epithelial cells
}

Mario Cazzola ${ }^{1,2,3}$, Luigino Calzetta ${ }^{2^{*}}$, Ermanno Puxeddu ${ }^{1,3}$, Josuel Ora ${ }^{3}$, Francesco Facciolo ${ }^{4}$, Paola Rogliani ${ }^{1,3}$ and Maria Gabriella Matera ${ }^{5}$

\begin{abstract}
Background: Nowadays, there is a considerable gap in knowledge concerning the mechanism(s) by which long-acting $\beta_{2}$-agonists (LABAs) and long-acting muscarinic antagonists (LAMAs) interact to induce bronchodilation. This study aimed to characterise the pharmacological interaction between glycopyrronium bromide and indacaterol fumarate and to identify the mechanism(s) leading to the bronchorelaxant effect of this interaction.

Methods: The effects of glycopyrronium plus indacaterol on the contractile tone of medium and small human isolated bronchi were evaluated, and acetylcholine and CAMP concentrations were quantified. The interaction was assessed by Bliss Independence approach.

Results: Glycopyrronium plus indacaterol synergistically inhibited the bronchial tone (medium bronchi, $+32.51 \%$ $\pm 7.86 \%$; small bronchi, $+28.46 \% \pm 5.35 \%$; $P<0.05$ vs. additive effect). The maximal effect was reached 140 min post-administration. A significant $(P<0.05)$ synergistic effect was observed during $9 \mathrm{~h}$ post-administration on the cholinergic tone, but not on the histaminergic contractility. Co-administration of glycopyrronium and indacaterol reduced the release of acetylcholine from the epithelium but not from bronchi, and enhanced cAMP levels in bronchi and epithelial cells $\left(P<0.05\right.$ vs. control), an effect that was inhibited by the selective $\mathrm{KCa}^{++}$channel blocker iberiotoxin. The role of CAMP-dependent pathway was confirmed by the synergistic effect elicited by the adenylate cyclase activator forskolin on glycopyrronium ( $P<0.05$ vs. additive effect), but not on indacaterol $(P>0.05$ vs. additive effect), with regard of the bronchial relaxant response and cAMP increase.
\end{abstract}

Conclusions: Glycopyrronium/indacaterol co-administration leads to a synergistic improvement of bronchodilation by increasing CAMP concentrations in both airway smooth muscle and bronchial epithelium, and by decreasing acetylcholine release from the epithelium.

Keywords: Glycopyrronium bromide, Indacaterol fumarate, Synergistic interaction, Human bronchi

\footnotetext{
* Correspondence: luigino.calzetta@uniroma2.it

${ }^{2}$ Department of Systems Medicine, Respiratory Pharmacology Research Unit,

University of Rome Tor Vergata, Via Montpellier 1, 00133 Rome, Italy

Full list of author information is available at the end of the article
} 


\section{Background}

Treatment for patients suffering from chronic obstructive pulmonary disease (COPD) not controlled by a single bronchodilator requires the addition of a second bronchodilator characterised by a different mechanism of action [1]. We strongly support this therapeutic approach because using multiple drugs in combination may allow lower doses of individual agents, decrease adverse effects, simplify medication regimens and improve compliance [2].

To date, there is solid clinical information for combining $\beta_{2}$-adrenoceptor agonists and anti-muscarinic agents [3-5], and recently, the true nature of the pharmacological interaction between long-acting $\beta_{2}$-agonists (LABAs) and longacting anti-muscarinic antagonists (LAMAs) was elucidated in both ex vivo studies performed in human isolated airways and clinical trials in COPD patients [6-8]. Indeed, it is now clear that combining low concentrations of a LABA with a LAMA leads to synergistic relaxation of human airway smooth muscle (ASM), which, in turn, provides optimised effectiveness while reducing the risk of side effects [9].

Although the synergistic interaction between the LAMA aclidinium bromide and the LABA formoterol fumarate has been deeply characterised from a pharmacological point of view [6], we cannot exclude the possibility that different LABA/LAMA combinations such as glycopyrronium bromide (NVA237) plus indacaterol fumarate (QAB149) may show a different pharmacological interaction [10].

Moreover, although several pathways have been proposed to clarify the intracellular cross-talk elicited by combining $\beta_{2}$-adrenoceptor agonists and anti-muscarinic agents in ASM cells and parasympathetic neurons [9, 11], there is still a considerable gap in knowledge with regard to the pharmacological mechanism(s) by which a LABA and a LAMA interact when they induce bronchodilation.

Therefore, this study aimed to characterise the nature (additive or synergistic) of the interaction between glycopyrronium and indacaterol in human isolated bronchi and bronchioles and to identify the mechanism(s) leading to a bronchorelaxant effect due to such an interaction.

\section{Methods}

\section{Ethical approval and informed consent}

Ethical approval and informed consent were obtained from the University of Rome 'Tor Vergata' (R.S. 107.14/ 2014, Rome, Italy), and were consistent with the guidelines of the 2009 National Committee of Bioethics, the recommendations of the National Committee of Biosafety, Biotechnology and Sciences (Italy) on the collection of biologic samples for research purposes, the 2010 Italian ethical and legal recommendations concerning biobanks and research biorepositories (Istituto Nazionale dei Tumori - Independent Ethics Committee, 2010) and the Comitato Nazionale per la Biosicurezza, le Biotecnologie e le Scienze per la Vita (Raccolta di campioni biologici a fini di ricerca, consenso informato, 2009; available at: http://www.governo.it/bioetica/gruppo_misto/Consenso_Informato_allegato_Petrini_2009.pdf).

\section{Human bronchial tissues \\ Tissue preparation}

Macroscopically normal airways were obtained from 23 patients (13 male and 10 female; aged $63.2 \pm 2.2$ years) undergoing surgery for lung cancer, without a history of chronic airway disease. Detailed demographic characteristics of patients, including smoking history, are reported in Table 1. Samples were taken from areas as distant as possible from the malignancy. Tissues were placed in KrebsHenseleit $(\mathrm{KH})$ buffer solution $(\mathrm{NaCl}, 119.0 \mathrm{mmol}$; $\mathrm{KCl}$, $5.4 \mathrm{mmol} ; \mathrm{CaCl}_{2}, 2.5 \mathrm{mmol} ; \mathrm{KH}_{2} \mathrm{PO}_{4}, 1.2 \mathrm{mmol} ; \mathrm{MgSO}_{4}$, $1.2 \mathrm{mmol}$; $\mathrm{NaHCO}_{3}, 25.0 \mathrm{mmol}$ and glucose, $11.7 \mathrm{mmol}$; $\mathrm{pH} 7.4)$ containing indomethacin $(5 \mu \mathrm{M})$ and transported to the laboratory. None of the patients received treatment with xanthines, $\beta_{2}$-adrenoceptor agonists, glucocorticosteroids or muscarinic antagonists. Preoperative lung function parameters were generally normal, and there were no signs of respiratory infections $[12,13]$.

\section{Isolated bronchi}

Airways studied in an isolated organ bath system were cut into rings (thickness: 1-2 $\mathrm{mm}$; diameter: 4-6 $\mathrm{mm}$ ) and transferred into a 10-mL High Tech 8 Channels Manual Compact Organ Bath system (Panlab Harvard Apparatus, Spain) containing $\mathrm{KH}$ buffer $\left(37^{\circ} \mathrm{C}\right)$ and aerated with $\mathrm{O}_{2} /$ $\mathrm{CO}_{2}$ (95\%:5\%). Tissues were allowed to equilibrate, and the KH buffer was constantly changed $[12,13]$.

\section{Epithelium removal}

In some experiments, the bronchial epithelium was mechanically removed by using a cotton-tipped applicator gently

Table 1 Demographic characteristics of human subjects

\begin{tabular}{ll}
\hline Characteristics & Value \\
\hline Gender (male/female) & $13 / 10$ \\
Age (years) & $63.2 \pm 2.2$ \\
Smoking status: & \\
$\quad$ Current & 14 \\
Former & 9 \\
Pack years & $45.5 \pm 8.4$ \\
FEV $_{1}(\mathrm{~L})$ & $2.54 \pm 0.14$ \\
$\mathrm{FEV}_{1}$ (\% predicted) & $93.15 \pm 3.24$ \\
$\mathrm{FEV}_{1}$ reversibility (\%) & $3.73 \pm 1.68$ \\
$\mathrm{FVC}(\mathrm{L})$ & $3.38 \pm 0.17$ \\
$\mathrm{FEV}_{1} / \mathrm{FVC}$ (\%) & $75.23 \pm 2.06$
\end{tabular}

Data are expressed as mean \pm SEM 
rubbed for $5 \mathrm{sec}$ on the luminal surface. It has been previously demonstrated that this manipulation does not penetrate the basal membrane and that the lamina propria remains almost intact [14].

\section{Videomorphometry}

Airways studied using videomorphometry were cut into precision cut lung slices (PCLS) (thickness: $<500 \mu \mathrm{m}$, diameter: $0.65 \pm 0.06 \mathrm{~mm}$ ) by a Motorised Advance Vibroslice equipped with ceramic blades (Campden Instruments, UK) and then mounted into a visual imaging and patching chamber connected to a Proportional Integral Derivative Temperature Controller with dual thermistor feedback CI7800 (Campden Instruments, UK), containing $\mathrm{KH}$ buffer $\left(37^{\circ} \mathrm{C}\right)$ aerated with $\mathrm{O}_{2} / \mathrm{CO}_{2}(95 \%: 5 \%)$. Tissues were allowed to equilibrate, and the $\mathrm{KH}$ buffer was constantly changed $[6,15]$.

\section{Human bronchial epithelial cells}

Primary human bronchial epithelial cells were harvested by gently scraping the luminal airway surface with a convex scalpel blade \#10, a procedure that does not penetrate the basal membrane. Collected epithelial cells were pooled in phosphate-buffered saline (PBS) and centrifuged at $500 \mathrm{~g}$ for $5 \mathrm{~min}$ at $4{ }^{\circ} \mathrm{C}$. Bronchial epithelial cells were resuspended, cultured with 1:1 mixture of LHC-9 and RPMI 1640 medium in a volume of $10^{6}$ cells $/ \mathrm{mL}$ and maintained at $37^{\circ} \mathrm{C}$ in a $5 \% \mathrm{CO}_{2}$ humidified incubator $[14,16]$.

\section{Contraction measurement}

\section{Preparation of isolated bronchi and tissue vitality}

Bronchial rings were connected to isometric force transducers Fort25 (WPI, UK). The signal was amplified by PowerLab 8/36 and Octal Bridge Amp system (ADInstruments, UK), recorded and analysed using the LabChart 7 interface software (ADInstruments, UK). Tissues were mounted on hooks and attached with a thread to a stationary rod and the other end was tied with a thread to an isometric force displacement transducer. Airways were allowed to equilibrate by flushing with fresh $\mathrm{KH}$ buffer solution. Passive tension was determined by gentle stretching of tissue $(0.5-1.0 \mathrm{~g})$ during equilibration. The isometric change in tension was measured by the transducer. The tissue vitality and maximal contractile responsiveness was assessed by acetylcholine at a $100 \mu \mathrm{M}$ concentration and/or by transmural stimulation (also called electrical field stimulation [EFS]) at $25 \mathrm{~Hz}$. These procedures allowed the bronchial rings to be correctly positioned between the hooks. When the response reached a plateau, the rings were washed thrice and allowed to further equilibrate $[12,14,17]$.

\section{Videomorphometry}

Bronchial contractility was evaluated by a stereo microscope Zenith SZR-10 and a digital Optikam-B5 managed by OptikaView7 software (Optika Microscopes, Italy). Small airways were allowed to equilibrate and continuously flushed with fresh $\mathrm{KH}$ buffer solution until the luminal area was stable. The area in the lumen was measured by the image processing and analysis software ImageJ [18].

\section{Acetylcholine and CAMP quantification}

Bath supernatant, cell culture medium and airway tissues were collected to quantify the release of acetylcholine and the concentrations of cyclic adenosine monophosphate (cAMP) by using enzyme-linked immunosorbent assay (ELISA) kits according to manufacturers' instructions in triplicate experiments (BioVision, CA, USA; Cells Biolabs, CA, USA).

Briefly, acetylcholine was converted to choline by adding acetylcholinesterase. After that, free choline was oxidised to betaine via the intermediate betaine aldehyde. The reaction generated products which reacted with the choline probe to generate colour, and the absorbance was measured at $570 \mathrm{~nm}$. Standard curves were prepared using cAMP standard, and sample concentrations were then determined. The detection range of this kit was $10 \mathrm{pM}$ to 5 nM cAMP (http://www.biovision.com/manuals/K615.pdf).

For cAMP detection, an anti-rabbit immunoglobulin G (IgG) polyclonal coating antibody was adsorbed onto a microtitre plate, and cAMP competed with peroxidase cAMP tracer for binding to the plate in the presence of rabbit anti-cAMP polyclonal antibody. Following incubation and wash steps, any peroxidase cAMP tracer bound to the plate was detected by addition of substrate solution. The coloured product formed was inversely proportional to the amount of cAMP. The reaction was terminated by addition of acid, and absorbance was measured at $450 \mathrm{~nm}$. Standard curves were prepared using cAMP standard, and sample concentrations were then determined. The detection range of this kit was 1 to $1000 \mathrm{pM} / \mathrm{mL}$ cAMP (http://www.cellbiolabs.com/sites/ default/files/STA-500-camp-elisa-kit.pdf).

\section{Study design \\ Study 1: Evaluation of the interaction between glycopyrronium plus indacaterol on the relaxation of human isolated bronchi pre-contracted with acetylcholine and histamine}

Following equilibration of the tissues, bronchial rings/ slices were submaximally contracted using acetylcholine ( $2 \mu \mathrm{M}$, inducing $70 \%$ of maximal contraction $\left.\left[\mathrm{EC}_{70}\right]\right)$. After a plateau was reached, semi-logarithmic concentration response curves (CRCs) were constructed for glycopyrronium and/or indacaterol, alone or together, at their isoeffective concentrations. Each CRC was obtained by the cumulative addition of glycopyrronium and/or 
indacaterol at intervals of $5-15 \mathrm{~min}$ to reach a stable level of relaxation before the next dose administration. In the control groups, cumulative concentrations of vehicle were administered and used as a time control. At the end of the experiments, papaverine $(100 \mu \mathrm{M})$ was added to the bronchial rings to determine the maximal relaxant response achievable for each isolated bronchus. These experiments were conducted in both an isolated organ bath system and a PCLS system in order to evaluate the relaxation associated with the airway smooth muscle strength and due to the increase in intra-luminal bronchial area $[6,15,19,20]$.

Further experiments were carried out in order to assess the pharmacological interaction between glycopyrronium and indacaterol in human isolated bronchi submaximally contracted using histamine $\left(20 \mu \mathrm{M},\left[\mathrm{EC}_{70}\right]\right)$.

\section{Study 2: Evaluation of the long-lasting interaction between glycopyrronium plus indacaterol in human isolated bronchi contracted using transmural stimulation}

Each isolated organ bath was fitted with two platinum plate electrodes connected to a stimulator 3165 Multiplexing Pulse Booster (Ugo Basile, VA - Italy) and placed alongside the bronchial rings for EFS. Experiments were performed using trains of $10 \mathrm{~Hz}$ EFS (biphasic pulse with a constant current of $10 \mathrm{~V}, 0.5 \mathrm{~ms}, 10 \mathrm{~s}$ ) one pulse every $5 \mathrm{~min}$ in order to simulate the vagus nerve firing $[13,21]$. After the start of the EFS trains, bronchi were treated for $60 \mathrm{~min}$ with glycopyrronium and/or indacaterol, alone or together, at $\mathrm{EC}_{20}$. After this step, tissues were washed thrice and the experiment progressed for $12 \mathrm{~h}$. During this time, the bronchial rings were flushed with $\mathrm{KH}$ buffer solution at a rate of $30 \mathrm{~mL} / \mathrm{h}$. At the end of the experiments, papaverine $(100 \mu \mathrm{M})$ was added to the bronchial rings to determine the maximal relaxant response achievable for each isolated bronchus $[6,15]$.

\section{Study 3: Influence of glycopyrronium and indacaterol on the release of acetylcholine and CAMP in human isolated bronchi and airway epithelial cells}

Human isolated bronchi and airway epithelial cells were submaximally stimulated with carbachol at $\mathrm{EC}_{70}$ and treated for $30 \mathrm{~min}$ with glycopyrronium and/or indacaterol, alone or together, at $\mathrm{EC}_{30}$ (glycopyrronium: 2.0 $\mathrm{nM}$, indacaterol: $5.8 \mathrm{nM}$ ). After that, the tissues and supernatants were collected to measure the concentration of acetylcholine and cAMP. The release of acetylcholine has been quantified also in isolated airways treated with histamine $(20 \mu \mathrm{M})$, in the presence or absence of glycopyrronium and/or indacaterol, alone or together, at $\mathrm{EC}_{30}$ (glycopyrronium: $2.02 \mu \mathrm{M}$, indacaterol: $4.30 \mu \mathrm{M}$ ). Experiments were also repeated in epithelium-denuded bronchi. In some experiments, human bronchi were pre-treated for $30 \mathrm{~min}$ with iberiotoxin (IbTX, $100 \mathrm{nM}$ ) [22-25] and the tetanus toxin (TeTX, $10 \mathrm{nM}$ ) [26-29] in order to block the $\mathrm{KCa}^{++}$ channels and inhibit the synaptic vesicle exocytosis of acetylcholine, respectively. In further experiments, primary human bronchial epithelial cells were pre-treated for 30 min with the organic cation transporter (OCT) inhibitor quinine $(100 \mu \mathrm{M})$ in order to reduce the release of endogenous acetylcholine from epithelial cells [14].

\section{Study 4: Role of CAMP-dependent pathway in glycopyrro- nium/indacaterol interaction}

The role of the cAMP-dependent pathway in modulating the glycopyrronium/indacaterol interaction has been assessed by treating for $30 \mathrm{~min}$ human isolated airways, previously submaximally contracted by carbachol at $\mathrm{EC}_{70}$, with glycopyrronium and/or indacaterol and/or the activator of the catalytic subunit of adenylate cyclase (AC) forskolin, alone or together in double and triple combinations administered at $\mathrm{EC}_{30}$ (forskolin: $56.2 \mathrm{nM}$; glycopyrronium and indacaterol: concentrations reported in study 3) [30]. Some experiments were carried out also in epitheliumdenuded bronchi. The relaxant response was recorded and tissues collected to quantify the concentration of cAMP. Papaverine $(100 \mu \mathrm{M})$ was used to determine the maximal relaxant response and identify the maximal production of cAMP achievable in human isolated bronchi.

\section{Analysis \\ Airways tone, acetylcholine release and CAMP concentrations}

The contractile relaxation of isolated bronchial rings/slices is expressed as a percentage of the maximal relaxation $\left(\mathrm{E}_{\max }\right.$, strength/luminal area) induced by papaverine $(100 \mu \mathrm{M})$ on the acetylcholine $\mathrm{EC}_{70}$ plateau. Appropriate curve-fitting to a sigmoidal model was used to calculate the effect $(E)$, the maximal response $\left(E_{\max }\right)$ and the dose inducing $50 \%$ and $70 \%$ maximal effect $\left(\mathrm{EC}_{50}\right.$ and $\mathrm{EC}_{70}$, respectively). The equation used was: response (variable slope) expressed as $\mathrm{Y}=$ Bottom $+($ Top - Bottom $) /\{1+$ $10^{\wedge}\left[\left(\operatorname{LogEC} \mathrm{C}_{50}-\mathrm{X}\right)^{*}\right.$ HillSlope $\left.]\right\}$, and the $\mathrm{pEC}_{50}$ value $\left(\mathrm{pEC}_{50}=-\operatorname{LogEC} \mathrm{C}_{50}\right)$ was used for statistical analysis of the potency [31].

The contractile response to EFS is expressed as a percentage of the effect induced by control EFS preceding the treatment with glycopyrronium or indacaterol. Polynomial curves were constructed by fitting models of biological data using nonlinear regression. Maximal reduction of the EFS contractile tension ( $E_{\max }$ relaxation) and the onset of action $\left(t_{1 / 2}\right.$, min, indicating the time to evoke a half of maximal relaxation) were identified. For every seven bronchial rings mounted in the isolated organ bath system, one was used as a time control [13, 31, 32].

The release of acetylcholine and the concentrations of cAMP were normalised to the wet weight of the isolated airways and expressed as a ratio of the control samples. 


\section{Interaction analysis}

The pharmacological interaction between glycopyrronium and indacaterol in human isolated bronchi was assessed using the Bliss Independence (BI) theory, one of the most commonly used models to study combined effects of substances in vivo and in vitro. The main assumption of the BI theory is that two or more agents act independently of one another. In particular, if the criterion is fulfilled, the mode, and possibly also the site of action of the compounds in the mixture, always differ. The BI theory for two and three agents are expressed by the following equation, respectively: $E(x, y)=E x+E y-\left(E x^{*} E y\right)$ and $E(x, y, z)=E x+E y+E z-$ $\left(E x^{*} E y\right)-\left(E x^{*} E z\right)-\left(E y^{*} E z\right)-\left(E x^{*} E y^{*} E z\right)$, where $E$ is the fractional effect, and $x, y$ and $z$ are the doses of the compounds in a combination experiment. If the combination effect is higher than the expected value from the above equations, the interaction is synergistic, while if this effect is lower, the interaction is antagonistic. Otherwise, the effect is additive and there is no interaction $[6,7,9,15,17,33]$. In this protocol, the $\mathrm{BI}$ equation was characterised by $\mathrm{x}=$ glycopyrronium and $\mathrm{y}=$ indacaterol in both studies 1 and 2 , and $\mathrm{z}=$ forskolin was included in study 4 . The BI approach was used to establish the expected relaxant effect and the expected increase of cAMP induced by the interaction between the investigated drugs at their isoeffective concentrations.

\section{Head-to-head comparison}

Previous published data on further LABA/LAMA combination (aclidinium/formoterol combination) are currently available [6]. Considering that those results [6] have been produced by our research group by performing ex vivo assays undergoing experimental condition identical to that of Study 2, as reported in the above described "Study design" section, we have carried out a head-to-head comparison of glycopyrronium/indacaterol vs. aclidinium/formoterol combinations administered at low concentrations inducing $\mathrm{EC}_{20}$, with regard of the pharmacological interaction elicited in course of EFS lasting $12 \mathrm{~h}$. The extent of synergistic interaction expressed as area under the curve at different time intervals $\left(\mathrm{AUC}_{0-\mathrm{t}}\right)$, onset of action, $\mathrm{E}_{\max }$ at plateau and duration of synergistic interaction have been analyzed.

\section{Statistical evaluation}

Values are presented as mean \pm SEM of $n=3$ bronchi from different subjects. The statistical significance was assessed by the t-test and one-way analysis of variance (ANOVA), and the level of statistical significance was defined as $P<0.05$. All data analysis was performed using computer software (GraphPad Prism 5, CA, USA) installed on an iMac computer.

\section{Drugs}

The test compounds are highly hygroscopic and were stored in a dry place. The solutions were prepared fresh every day. The products used in this study were obtained from the following sources, and stock solutions were prepared as indicated below: acetylcholine (Sigma-Aldrich, Italy), carbachol (Sigma-Aldrich, Italy), histamine (Sigma-Aldrich, Italy), IbTX (Sigma-Aldrich, Italy), indomethacin (Sigma-Aldrich, Italy), glycopyrronium bromide (NVA237, Novartis), forskolin (Sigma-Aldrich, Italy), papaverine (Sigma-Aldrich, Italy), indacaterol fumarate (QAB149, Novartis), quinine (Sigma-Aldrich, Italy) and TeTX (Sigma-Aldrich, Italy).

Acetylcholine, carbachol, histamine and papaverine were dissolved in distilled water; glycopyrronium, indacaterol and forskolin were dissolved in dimethylsulfoxide (DMSO); indomethacin was dissolved in ethanol and then diluted in $\mathrm{KH}$ buffer solution. The maximal amount of ethanol $(0.02 \%)$ did not influence isolated tissue response $[7,13-15,17,19,33]$. Compounds were stored in small aliquots at $-80{ }^{\circ} \mathrm{C}$ until their use.

\section{Results \\ Study 1 \\ Isolated segmental bronchi}

Both glycopyrronium and indacaterol induced potent concentration-dependent relaxation of human isolated bronchi submaximally pre-contracted with acetylcholine (-Log dose concentration inducing $50 \%$ maximal effect [pEC ${ }_{50}$ ] glycopyrronium: $8.44 \pm 0.02 ; \mathrm{pEC}_{50}$ indacaterol: $7.39 \pm 0.29$ ); however, glycopyrronium was more potent than indacaterol $(P<0.05)$. Both drugs completely abolished the contractile tone induced by acetylcholine $\mathrm{EC}_{70}$ (maximal effect $\left[E_{\max }\right]$ glycopyrronium: $99.68 \% \pm 0.32 \%$; $E_{\max }$ indacaterol: $92.28 \% \pm 0.26 \%$ ) (Fig. 1a). No significant modification in bronchial tone was noted with the control vehicle used in the experiments $(P>0.05)$.

Glycopyrronium plus indacaterol induced a synergistic relaxant response in human isolated bronchi submaximally pre-contracted with acetylcholine compared to the expected response predicted by the BI theory (Fig. 1b). In particular, the interaction between glycopyrronium and indacaterol was significantly synergistic $(P<0.05)$ at low concentrations (glycopyrronium: $0.4-3.4 \mathrm{nM}$, indacaterol: $0.1-40.0 \mathrm{nM}$ ) and induced a higher relaxant response of $+32.51 \% \pm 7.86 \%$ than the expected additive effect predicted by the BI theory (Fig. 1c).

Glycopyrronium and indacaterol induced similar concentration-dependent relaxation of human isolated bronchi submaximally pre-contracted with histamine (pEC $\mathrm{p}_{50}$ glycopyrronium: $4.99 \pm 0.15 ; \mathrm{pEC}_{50}$ indacaterol: $4.52 \pm 0.18)$, although both drugs did not completely abolish the contractile tone induced by histamine $\mathrm{EC}_{70}$ $\left(\mathrm{E}_{\max }\right.$ glycopyrronium: $85.20 \% \pm 8.58 \%$; $\mathrm{E}_{\max }$ indacaterol: $70.76 \% \pm 11.98 \%$ ) (Fig. 1d). Glycopyrronium plus indacaterol elicited additive effect in human isolated bronchi submaximally pre-contracted with histamine, 


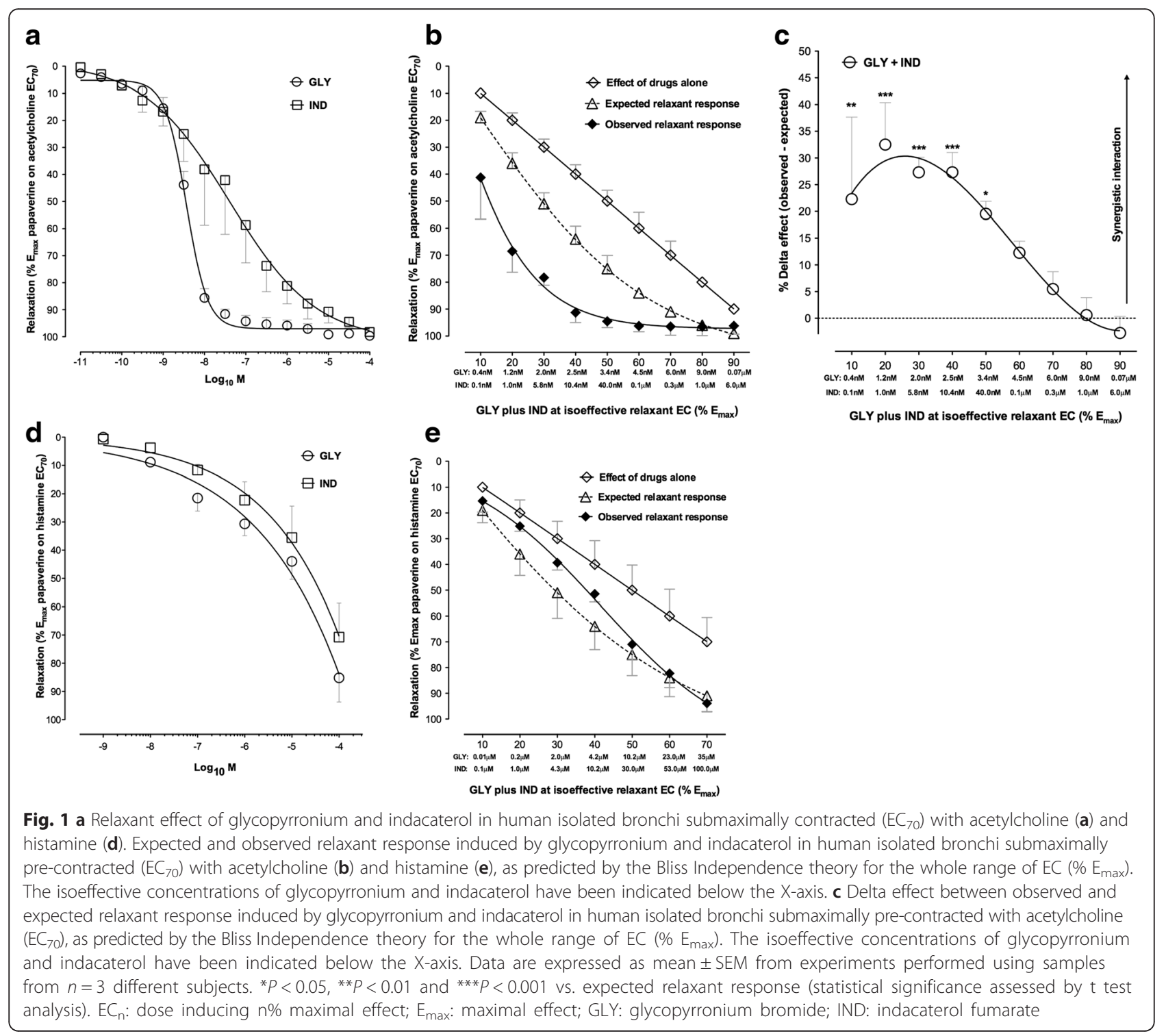

when compared with the expected response predicted by the BI theory (Fig. 1e) $(P>0.05$ vs. expected relaxant effect).

\section{Small airways using PCLS}

Both glycopyrronium and indacaterol induced potent concentration-dependent relaxation of human PCLSs submaximally pre-contracted with acetylcholine $\left(\mathrm{pEC}_{50}\right.$ glycopyrronium: $8.45 \pm 0.23$; $\mathrm{pEC}_{50}$ indacaterol: $6.53 \pm$ 0.18 ); however, glycopyrronium was more potent than indacaterol $(P<0.01)$. Both drugs completely abolished the bronchial contraction induced by acetylcholine $\mathrm{EC}_{70}$ $\left(\mathrm{E}_{\max }\right.$ glycopyrronium: $103.01 \% \pm 1.59 \%$; $\mathrm{E}_{\max }$ indacaterol: $94.85 \% \pm 1.70 \% ; P<0.05)$ (Fig. $2 a$ ). No significant modification in bronchial tone was noted with the control vehicle used in the experiments $(P>0.05)$.
Glycopyrronium and indacaterol induced a synergistic relaxant response in human PCLSs submaximally precontracted with acetylcholine compared to the expected response predicted by the BI theory (Fig. 2b). In particular, the interaction between glycopyrronium and indacaterol was significantly $(P<0.01)$ synergistic at low concentrations (glycopyrronium: 0.2-1.5 $\mathrm{nM}$, indacaterol: 0.03-0.13 $\mu \mathrm{M}$ ) and induced an increased relaxant response of $+28.46 \% \pm$ $5.35 \%$ compared to the expected additive response predicted by the BI theory (Fig. 2c).

\section{Study 2}

Low concentrations of glycopyrronium and indacaterol ( 0.3 and $30 \mathrm{nM}$, respectively) yielded an approximately $20 \%$ relaxant response on the bronchial contractile tone induced by EFS $10 \mathrm{~Hz}$ during the first hour of the experiment (Fig. $3 a$ and $b$ ). In the presence of study drugs 

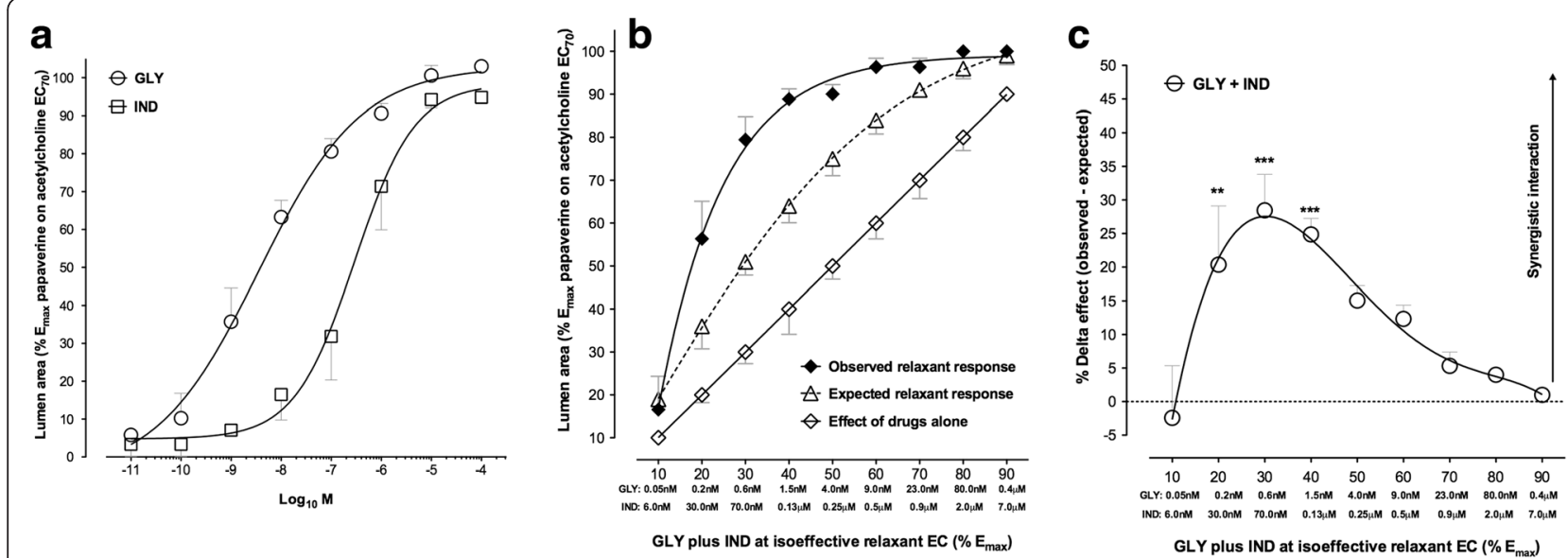

Fig. 2 a Effect of glycopyrronium and indacaterol on the luminal area of human small airways using PCLS submaximally contracted with acetylcholine $\left(E C_{70}\right)$. $\mathbf{b}$ Expected and observed relaxant response induced by glycopyrronium and indacaterol in human small airways using PCLS submaximally precontracted with acetylcholine ( $\left.\mathrm{EC}_{70}\right)$, as predicted by the Bliss Independence theory for the whole range of $\mathrm{EC}\left(\% \mathrm{E}_{\max }\right)$. The isoeffective concentrations of glycopyrronium and indacaterol have been indicated below the X-axis. c Delta effect between observed and expected relaxant response induced by glycopyrronium and indacaterol in human small airways using PCLS submaximally pre-contracted with acetylcholine (EC $\mathrm{C}_{70}$ ), as predicted by the Bliss Independence theory for the whole range of $\mathrm{EC}\left(\% \mathrm{E}_{\max }\right)$. The isoeffective concentrations of glycopyrronium and indacaterol have been indicated below the $X$-axis. Data are expressed as mean \pm SEM from experiments performed using samples from $n=3$ different subjects. ${ }^{*} P<0.01$ and ${ }^{* *} P<0.001$ vs. expected relaxant response (statistical significance assessed by t test analysis). EC $C_{n}$ : dose inducing n\% maximal effect; $E_{\text {max: }}$ maximal effect; GLY: glycopyrronium bromide; IND: indacaterol fumarate; PCLS: precision cut lung slice

in the bath, and before the wash time, both drugs administered alone were unable to elicit a $50 \%$ reduction in the contractile response to EFS. On the contrary, the isoeffective mixture $\left(\mathrm{EC}_{20}\right)$ of low concentrations of glycopyrronium and indacaterol produced a maximal relaxation of $58.82 \% \pm 15.32 \%$ in the presence of the drugs, and this relaxant effect increased up to $71.95 \% \pm 2.37 \%$ at $175 \mathrm{~min}$ of the experiment, as measured during the wash time (in the absence of drugs). The onset of action for the mixture of drugs was $18.30 \pm 9.30 \mathrm{~min}$, and the relaxant effect remained stable for up to $12 \mathrm{~h}$ of the experiment $(51.76 \% \pm 13.57 \%)$. The observed relaxant effect, induced by the drug mixture, was considerably higher when compared to the expected relaxant response during the first $9 \mathrm{~h}$ of the experiment (Fig. 3c).

The BI interaction analysis shows that low concentrations of glycopyrronium and indacaterol produced a significant $(P<0.001)$ synergistic relaxant effect on the transmural stimulation of human isolated bronchi for $9 \mathrm{~h}$ after treatment. The maximal relaxant response was $+32.18 \% \pm 5.44 \%$ higher compared to the expected additive response predicted by the BI theory, and was reached by 140 min of the study (Fig. 3d).

\section{Study 3}

Glycopyrronium and indacaterol, administered alone or in combination at low concentrations, reduced the release of acetylcholine from human isolated bronchi (glycopyrronium: $-50.38 \% \pm 1.77 \%$, indacaterol: $-32.81 \% \pm 3.45 \%$; $P<0.001$ vs. control; combination, $-16.82 \% \pm 2.32 \%$;
$P<0.01$ vs. control). Removal of the epithelium resulted in inhibition of the effects of both glycopyrronium and indacaterol $(+38.95 \% \pm 2.81 \%$ and $+39.90 \% \pm 4.15 \%$, respectively; $P<0.01$ vs. epithelium intact bronchi) but did not lead to modification of the acetylcholine concentrations in the supernatant when the drugs were administered in combination $(P>0.05$ vs. epithelium intact bronchi). Inhibition of $\mathrm{KCa}^{++}$channels by IbTx completely abolished the effect of glycopyrronium and indacaterol, administered alone or in combination, on the acetylcholine release $(P>0.05$ vs. control). The blockade of synaptic vesicle exocytosis by TeTX inhibited the release of acetylcholine $(-59.99 \% \pm 1.19 \%, P<0.001$ vs. control), and both glycopyrronium and indacaterol further enhanced this effect (overall, $-68.38 \% \pm 1.79 \%, P<0.001$ vs. control) (Fig. 4a).

No modification of acetylcholine release from primary human bronchial epithelial cells was observed at low concentrations of glycopyrronium and indacaterol $(P>0.05$ vs. control), whereas the glycopyrronium/indacaterol combination significantly reduced the acetylcholine concentrations in the culture medium $(-36.63 \% \pm 4.69 \%, P<0.01$ vs. control). While the OCT inhibitor quinine inhibited the release of endogenous acetylcholine from epithelial cells $(-37.13 \% \pm 3.29 \%, P<0.01$ vs. control) in the presence of glycopyrronium and indacaterol $(-38.28 \% \pm$ $5.73 \%$ and $-24.33 \% \pm 5.65 \%$, respectively; $P<0.05$ vs. control), it did not influence $(P>0.05)$ the effectiveness of the glycopyrronium/indacaterol combination $(-31.26 \% \pm$ $5.24 \%, P<0.01$ vs. control) (Fig. 4b). 

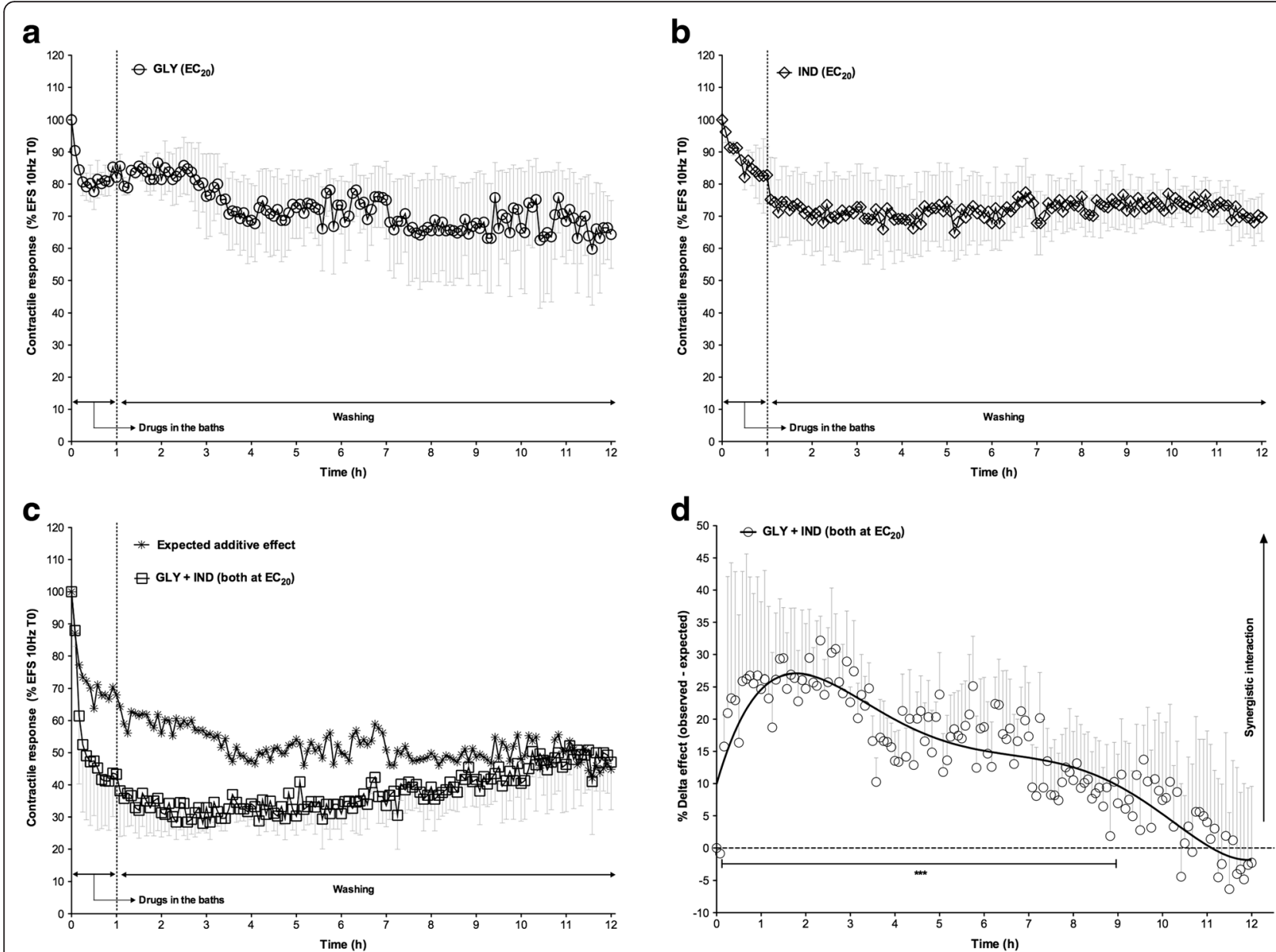

Fig. 3 Duration of action for glycopyrronium (a) and indacaterol (b) in human isolated bronchi stimulated using EFS at $10 \mathrm{~Hz}$ to mimic the vagus nerve firing. The observed and expected additive relaxant effect of the drug mixture (both at $\mathrm{EC}_{20}$, as predicted by the Bliss Independence theory) are reported during the $12 \mathrm{~h}$ of the study (c). Delta effect between observed and expected relaxant response, as predicted by the Bliss Independence theory, induced by glycopyrronium and indacaterol in human isolated bronchi contracted using EFS at $10 \mathrm{~Hz}$ to mimic the vagus nerve firing during $12 \mathrm{~h}$ of the study (d). Data are expressed as mean \pm SEM from experiments performed using samples from $n=3$ different subjects. ${ }^{* * *} P<0.001$ vs. expected relaxant response (statistical significance assessed by two-way ANOVA). $\mathrm{EC}_{n}$ : dose inducing $\mathrm{n} \%$ maximal effect; EFS: electrical field stimulation; GLY: glycopyrronium bromide; IND: indacaterol fumarate

Histamine significantly increased the release of acetylcholine $(+61.12 \% \pm 19.25 \%, P<0.05$ vs. untreated airways), whereas neither glycopyrronium nor indacaterol administered alone and in combination significantly reduced the histamine-induced acetylcholine release $(-4.99 \% \pm 15.33 \%$ vs. histamine-stimulated airways). Neither epithelium nor TeTX significantly modified the release of acetylcholine mediated by histamine, also in the presence of glycopyrronium and/or indacaterol $(P>0.05$ vs. epithelium intact airways and TeTX untreated airways) (Fig. 4c).

Although the cAMP concentrations in the isolated bronchi were significantly enhanced with indacaterol $(+167.60 \% \pm 2.33 \%, P<0.001$ vs. control) but not with glycopyrronium $(P>0.05$ vs. control), combining low concentrations of glycopyrronium plus indacaterol induced a noteworthy increase in cAMP concentrations $(+479.44 \% \pm$ $62.40 \%, P<0.01$ vs. control). In epithelium-denuded bronchi, the modulation of cAMP by glycopyrronium and indacaterol was not different compared with that observed in epithelium intact bronchi $(P>0.05)$. Pretreatment with IbTX inhibited the effects of indacaterol and the glycopyrronium/indacaterol combination on the increase of cAMP concentrations $(P<0.01$ vs. IbTX untreated) (Fig. 4d).

Neither glycopyrronium nor indacaterol modified the cAMP concentrations of primary human bronchial epithelial cells $(P>0.05$ vs. control), whereas the combination of low concentrations of glycopyrronium plus indacaterol induced a significant increase in cAMP concentrations $(+29.08 \% \pm 7.05 \%, P<0.05)$ compared with the control (Fig. 4e). 

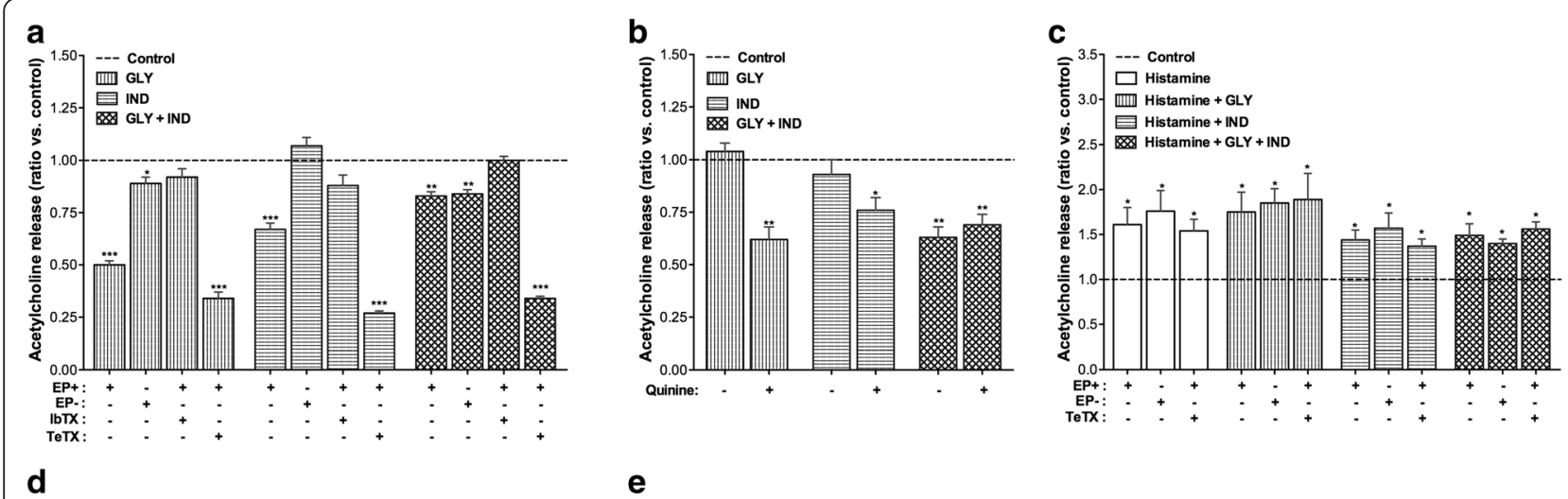

d
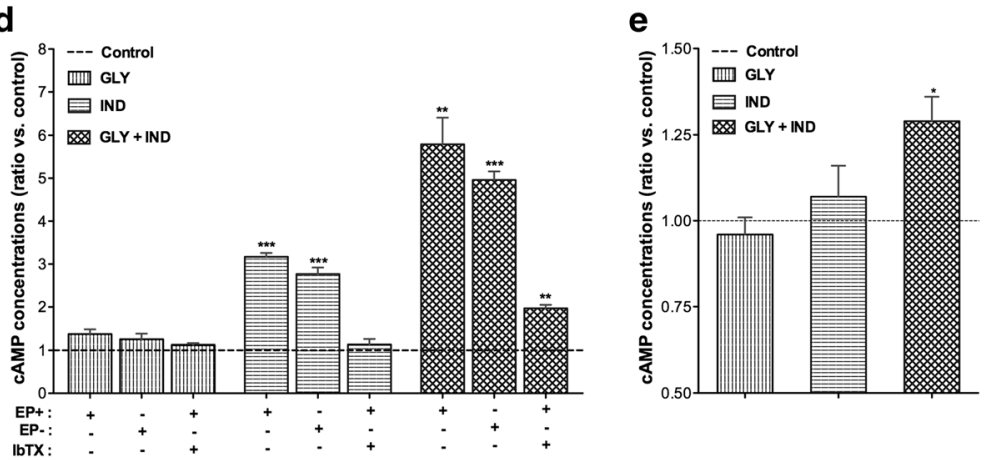

Fig. 4 a Effect of low concentrations ( $E C_{30}$ ) of glycopyrronium and indacaterol on the release of acetylcholine from intact and denuded epithelium bronchi and the influence of iberiotoxin $(100 \mathrm{nM})$ and tetanus toxin $(10 \mathrm{nM})$. b Effect of low concentrations $\left(\mathrm{EC}_{30}\right)$ of glycopyrronium and indacaterol on the release of acetylcholine from primary bronchial epithelial cells submaximally stimulated with carbachol $\left(E C_{70}\right)$, and influence of quinine (100 $\left.\mu M\right)$. c Effect of low concentrations ( $\mathrm{EC}_{30}$ ) of glycopyrronium and indacaterol on the histamine-induced release of acetylcholine from intact and denuded epithelium bronchi, and the influence of tetanus toxin $(10 \mathrm{nM})$. d Effect of low concentrations ( $\mathrm{EC}_{30}$ ) of glycopyrronium and indacaterol on the CAMP concentrations in intact and denuded epithelium bronchi and influence of iberiotoxin (100 nM). e Effect of low concentrations $\left(\mathrm{EC}_{30}\right)$ of glycopyrronium and indacaterol on the CAMP concentrations in primary bronchial epithelial cells. Data are expressed as mean \pm SEM from experiments performed using samples from $n=3$ different subjects. ${ }^{*} P<0.05,{ }^{* *} P<0.01$ and ${ }^{* * *} P<0.001$ vs. control (dotted line) (statistical significance assessed by t test analysis). cAMP: cyclic adenosine monophosphate; $E C_{n}$ : dose inducing $n \%$ maximal effect; $E P+$ : epithelium intact; $E P-$ :

epithelium denuded; GLY: glycopyrronium bromide; IbTX: iberiotoxin; IND: indacaterol fumarate; TeTX: tetanus toxin

\section{Study 4}

Low concentrations of glycopyrronium/indacaterol and glycopyrronium/forskolin combinations inducing alone $\mathrm{EC}_{30}$ synergistically increased the relaxant response of isolated airways submaximally pre-contracted with acetylcholine $(+27.32 \% \pm 2.83 \%$ and $+30.19 \% \% \pm 6.87 \%$, respectively; $P<0.05$ vs. expected additive effect), whereas the indacaterol/forskolin combination elicited only an additive effect when compared with the expected relaxation predicted by the BI theory (Fig. 5a). Although the triple combination glycopyrronium/indacaterol/forskolin produced a greater broncholitic effect than that expected by the BI theory, $(+22.29 \% \pm 8.67 \%)$, the extent of this effect was not significant when compared with the additive effect as predicted by the BI theory $(P>0.05)$ (Fig. 5b).

The glycopyrronium/indacaterol and glycopyrronium/forskolin combinations both synergistically increased the concentrations of cAMP (overall, $+17.98 \% \pm$ $6.29 \%, P<0.05$ vs. expected additive effect), whereas the indacaterol/indacaterol and triple glycopyrronium/indacaterol/forskolin combinations induced only additive effects, when compared with the expected effect as predicted by the BI theory $(P>0.05)$. The presence of epithelium did not modulate the interaction characteristics for all drugs combinations ( $P>0.05$ vs. epithelium-denuded bronchi) (Fig. 5c).

The increase of cAMP elicited by the double and triple drugs combinations was significantly correlated with the extent of bronchial relaxant response (Pearson's r 0.95, $\mathrm{R}^{2}$ 0.90; $\left.P<0.05\right)$ (Fig. 5d).

\section{Head-to-head comparison}

The head-to-head comparison of glycopyrronium/indacaterol vs. aclidinium/formoterol combinations indicated that the overall extent of synergistic interaction $\left(\mathrm{AUC}_{0-12}\right)$ and onset of action $\left(\mathrm{T}_{1 / 2}\right)$ were similar for both these drugs combinations $(P>0.05)$. Synergism $\mathrm{AUC}_{0-3}$ and $\mathrm{AUC}_{0-6}$ induced by aclidinium/formoterol combination was significantly greater that that elicited by glycopyrronium/ indacaterol combination $(+41.70 \pm 13.49, P<0.01)$, as confirmed by the difference in $E_{\max }$ at plateau $(+17.01 \% \pm$ $7.56 \%, P<0.01)$. On the other hand, the analysis of the 


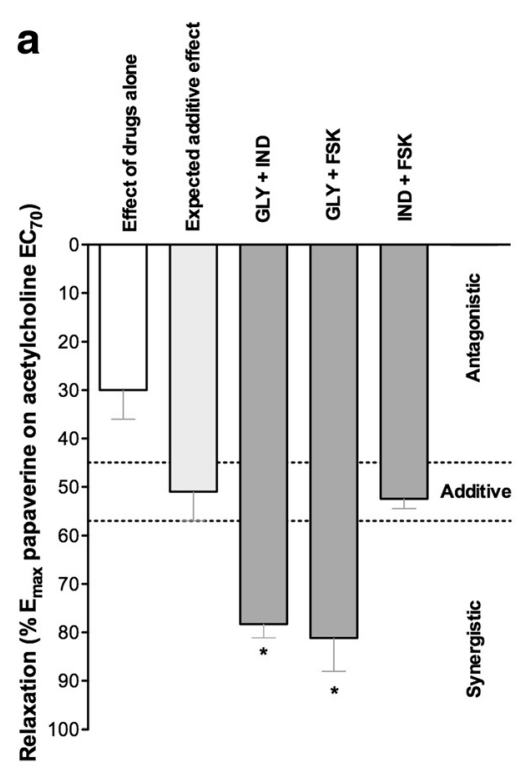

C

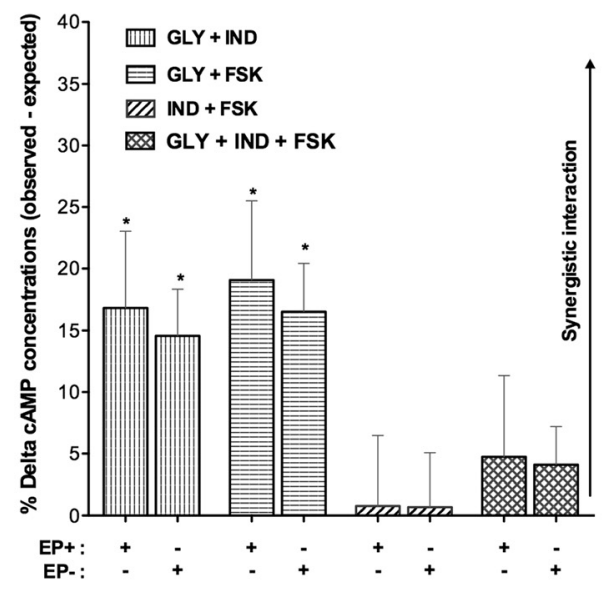

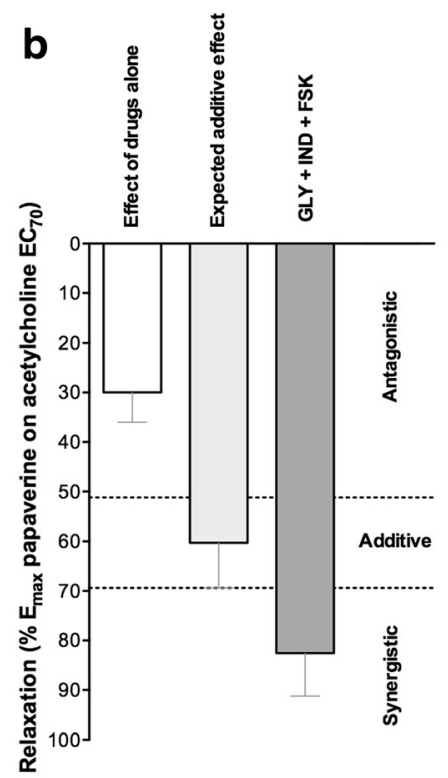

d

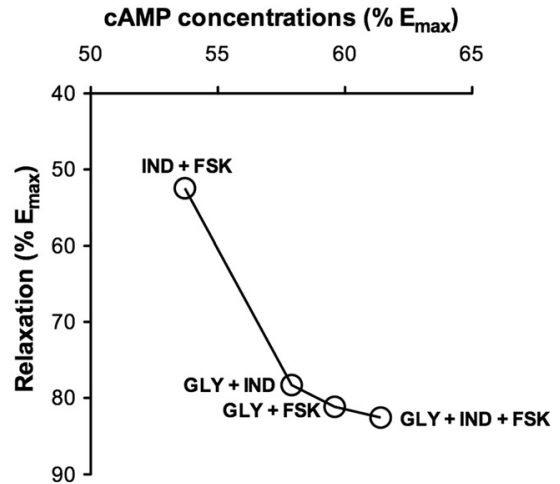

Fig. 5 Expected and observed relaxant response induced by low concentrations $\left(E C_{30}\right)$ of glycopyrronium, indacaterol and forskolin administered as double (a) or triple (b) combinations in human isolated bronchi submaximally pre-contracted with acetylcholine $\left(\mathrm{EC}_{70}\right)$, as predicted by the Bliss Independence theory. $\mathbf{c}$ Influence of low concentrations ( $\mathrm{EC}_{30}$ ) of glycopyrronium, indacaterol and forskolin administered as double and triple combinations on the delta effect between observed and expected cAMP concentrations in human isolated bronchi submaximally pre-contracted with acetylcholine $\left(E_{70}\right)$, as predicted by the Bliss Independence theory. $\mathbf{d}$ Correlation between the CAMP concentrations induced by glycopyrronium, indacaterol and forskolin combinations and relaxant response of human isolated airways submaximally pre-contracted with acetylcholine (EC $\mathrm{C}_{70}$ ). Data are expressed as mean \pm SEM from experiments performed using samples from $n=3$ different subjects. ${ }^{*} P<0.05$ vs. expected additive effect as predicted by Bliss Independence equations (statistical significance assessed by t test analysis). CAMP: cyclic adenosine monophosphate; EC $_{70}$ : dose inducing 70 \% maximal effect; $E_{\max }$ : maximal effect; EP+: epithelium intact; EP-: epithelium denuded; FSK: forskolin; GLY: glycopyrronium bromide; IND: indacaterol fumarate

duration of synergism indicated significant superiority of glycopyrronium/indacaterol combination vs. aclidinium/ formoterol combination $(+3 \mathrm{~h}, P<0.05)$. Detailed comparison results are reported in Table 2.

\section{Discussion}

The results of this study demonstrate that both glycopyrronium and indacaterol have the ability to induce potent, significant and long-lasting relaxation of both medium and small human isolated bronchi pre-contracted with acetylcholine. The co-administration of glycopyrronium and indacaterol produces a synergistic inhibition of ASM tone via modulating the cAMP-dependent pathway, especially when these drugs are administered at low concentrations. Intriguingly, when glycopyrronium and indacateriol were administered at low concentrations in our experimental setting, their ratio was consistent with that of the currently approved fixed dose combinations 
Table 2 Comparison of the synergism elicited by glycopyrronium/ indacaterol vs. aclidinium/formoterol combinations in human isolated bronchi stimulated by EFS at $10 \mathrm{~Hz}$

\begin{tabular}{|c|c|c|c|}
\hline & $\begin{array}{l}\text { Glycopyrronium/ } \\
\text { indacaterol }\end{array}$ & $\begin{array}{l}\text { Aclidinium/ } \\
\text { formoterol }\end{array}$ & $P$ \\
\hline \multicolumn{4}{|l|}{$\overline{A \cup C}$} \\
\hline $0-1 \mathrm{~h}$ & $20.22 \pm 8.38$ & $27.39 \pm 3.51$ & NS \\
\hline $0-3 h$ & $72.65 \pm 18.72$ & $108.25 \pm 10.12$ & $* *$ \\
\hline $0-6 \mathrm{~h}$ & $127.26 \pm 28.81$ & $175.07 \pm 16.86$ & $* *$ \\
\hline $0-9 h$ & $164.64 \pm 41.88$ & $186.40 \pm 29.87$ & NS \\
\hline $0-12 \mathrm{~h}$ & $175.43 \pm 61.55$ & $159.25 \pm 53.19$ & NS \\
\hline Onset $\left(T_{1 / 2}, \mathrm{~min}\right)$ & $18.30 \pm 9.30$ & $15.5 \pm 3.5$ & NS \\
\hline$E_{\max }$ (plateau, \%) & $25.93 \pm 9.41$ & $42.94 \pm 7.56$ & \\
\hline $\begin{array}{l}\text { Duration of } \\
\text { synergism (h) }\end{array}$ & $9: 00 \pm 0: 11$ & $6: 00 \pm 0: 12$ & \\
\hline
\end{tabular}

$\mathrm{AUC}_{(0-\mathrm{t})}$ : area under the curve for specific time intervals; EFS: electrical field stimulation; NS: not significant $(P>0.05)$. Data are expressed as mean \pm SEM from experiments performed using samples from $n=3$ different subjects. ${ }^{* *} P<0.01$ and ${ }^{* *} P<0.001$ (statistical significance assessed by two-way ANOVA)

(FDCs), namely 15.6/27.5 $\mu \mathrm{g}$ in United States and 50/ $110 \mu \mathrm{g}$ in European Union [34, 35].

Overall, the functional data described in this study are consistent with those concerning the pharmacological characterisation of the interaction between aclidinium bromide and formoterol fumarate in human isolated bronchi [6]. Nevertheless, the glycopyrronium/indacaterol combination produced a greater synergistic interaction in both medium bronchi and bronchioles when compared with that induced by the aclidinium bromide/ formoterol fumarate combination. In addition, we must highlight that while formoterol fumarate administered alone did not completely relax small airways, indacaterol was able to abolish the contractile tone of PCLS preparations [6]. As expected, the duration of the synergistic effect of glycopyrronium plus indacaterol was markedly longer than that elicited by combining aclidinium bromide with formoterol fumarate. In fact, a significant synergism between glycopyrronium and indacaterol was detectable for at least $9 \mathrm{~h}$. On the contrary, combining aclidinium bromide with formoterol fumarate induced a greater post-administration bronchorelaxant peak, though the synergism was significant for only $6 \mathrm{~h}$ after the administration of the two drugs [6]. In any case, the head-to-head comparison of glycopyrronium/indacaterol vs. aclidinium/formoterol combinations indicated that the overall extent of synergistic interaction and onset of action were similar for both these LABA/LAMA combinations, at least undergoing the experimental conditions set up in our ex vivo model of human isolated bronchi. In fact, we must consider that a recent synthesis of the currently available clinical data suggested for a rank of effectiveness among the approved doses of LAMA/ LABA FDCs, with glycopyrronium/indacaterol (15.6/
$27.5 \mathrm{mg}$ and $50 / 110 \mathrm{mg}$ ) eliciting greater $\mathrm{FEV}_{1}$ increase than aclidinium/formoterol $(400 / 12 \mathrm{mg})$ in COPD patients, when compared with the respective monocomponents [36]. However, this discrepancy may be related with the fact that glycopyrronium/indacaterol and aclidinium/formoterol combinations, administered at the currently approved doses, may be not delivered into the lung at isoeffective concentrations [36].

When one agent interacts with its specific G proteincoupled receptor (GPCR), the effect of another agent on its GPCR may change, leading to a possible pharmacological interaction [37, 38]. Since our study has provided evidences for a synergistic cross-talk between an anti-muscarinic agent and a $\beta_{2}$-adrenoceptor agonist undergoing cholinergic stimulation, we have investigated whether the inhibition of muscarinic GPCRs may transmit the signal to $\beta_{2}$-adrenoceptor GPCR also in course of histamine-induced bronchoconstriction. The bronchial contractile tone induced by histamine is mediated by both direct activation of histaminergic receptors expressed on human ASM, and facilitator effect of the acetylcholine release from parasympathetic nerve terminals [38-40]. The findings of our study represent a significant step forward the study of Aizawa et al. [40], by providing the evidence that the increase in isometric tension elicited by histamine is manly mediated by the resease of acetylcholine via the direct action of histamine on the vagus efferent nerve terminals, independently by neural conduction. In fact, neither TeTX nor epithelium altered the histamine-induced increase of acetylcholine release. Furthermore, neither glycopyrronium nor indacaterol were able to reduce the release of acetylcholine at control levels, even when these drugs were administered in combination. Therefore, the lack of synergism between glycopyrronium and indacaterol on the human ASM contractility histaminemediated may be explained by the lack of a direct influence of either these drugs on the bronchial histaminergic pathway. Our results confirm that both anti-muscarinic agents and $\beta_{2}$-adrenoceptor agonists are less potent and effective in reducing the bronchial tone elicited by histamine when compared with their impact on the cholinergic tone [19, 33, 41], and that no cross-talk exists between muscarinic and to $\beta_{2}$-adrenoceptor GPCRs in course of histaminergic stimulation.

Nevertheless, it has been recently reported that the bronchoprotection by a LABA may be synergistically enhanced by a LAMA, at least in vivo in guinea-pigs [42, 43]. Indeed, the results of these studies are in evident contrast with our findings, and probably any discrepancy may be related with the considerable differences between our methodological approach and that performed by Smit and colleagues [42, 43]. However, we must highlight that the data we have presented here may be of great interest, because the responses of autonomic nervous system and ASM are specific for species and for tissues [40], and 
results obtained from human isolated tissues have certainly a greater translational potential when compared with those obtained from animal models [44].

In this study, we have also attempted to elucidate the mechanism(s) underlying the bronchorelaxant interaction between LABAs and LAMAs.

We assumed that the activation of $\beta_{2}$-adrenoceptors by indacaterol would have no effect on the release of acetylcholine from parasympathetic nerves, as previously documented by using human isolated trachea stimulated with the $\beta_{2}$-adrenoceptor agonist isoprenaline [45]. On the contrary, our data showed that indacaterol was able to reduce the release of acetylcholine, a phenomenon that was dependent by the bronchial epithelium and reverted by blocking the IbTX-sensitive $\mathrm{KCa}^{++}$channels.

Since we have confirmed the neuronal origin of acetylcholine by inhibiting its release using TeTX, we can assume that in human bronchi indacaterol has a protective role against the neuronal release of acetylcholine. There is experimental documentation in laboratory animals that $\beta_{2}$-adrenoceptor stimulation may elicit a paradoxical facilitation of acetylcholine release from isolated trachea via the activation of a cAMP/cAMP-dependent protein kinase cascade [45]. Our data indicate that this is not the case in human bronchial tissue.

Surprisingly, contrary to our assumption that an antimuscarinic agent would facilitate neurogenic transmission due to inhibition of the pre-synaptic muscarinic $\mathrm{M}_{2}$ autoreceptor, glycopyrronium inhibited the parasympathetic release of acetylcholine [9]. So far, it is well known that anti-muscarinic agents are not specifically selective for the post-synaptic muscarinic $M_{3}$ receptor [46]. In fact, LAMAs may bind to human muscarinic $\mathrm{M}_{1}-\mathrm{M}_{5}$ receptors in a concentration-dependent manner, although they dissociate more slowly from the muscarinic $\mathrm{M}_{3}$ receptor than they do from the others [47]. In particular, glycopyrronium showed no selectivity in its binding to the muscarinic $M_{1}-M_{3}$ receptors [48]. However, a 3-5fold higher affinity was observed for the muscarinic $M_{3}$ receptor compared to the muscarinic $\mathrm{M}_{1}$ and $\mathrm{M}_{2}$ receptors, and the Schild plot analysis demonstrated that glycopyrronium has a higher affinity for muscarinic $M_{1}$ and $\mathrm{M}_{3}$ receptors compared to the muscarinic $\mathrm{M}_{2}$ autoreceptor [48]. Thus, at the level of post-ganglionic parasympathetic neurons, glycopyrronium prevalently inhibits the muscarinic $\mathrm{M}_{1}$ receptor expressed on the body cell compared with the inhibition elicited on the muscarinic $\mathrm{M}_{2}$ autoreceptor localised on the post-ganglionic fibre [49]. Since the muscarinic $M_{1}$ receptor is facilitatory to nicotinic receptors and is involved in setting the efficacy of ganglionic transmission $[49,50]$, the overall inhibitory effect of glycopyrronium leads to reduced parasympathetic transmission.

Analogous to indacaterol, modulation of the acetylcholine release by glycopyrronium was related with the integrity of the bronchial epithelium and the functionality of IbTX-sensitive $\mathrm{KCa}^{++}$channels. Unfortunately, we did not detect any synergistic effect on the inhibitory release of parasympathetic acetylcholine when low concentrations of indacaterol and glycopyrronium were administered in combination.

The autonomic control of human ASM tone is primarily mediated by the release of acetylcholine from parasympathetic fibers [51]. However, a non-neuronal cholinergic system exists at the level human airways [52]. The synthesis, recycling, storage and release of non-neuronal acetylcholine is mediated by several mechanisms such as choline acetyltransferase (ChAT), ChAT-like enzymes, carnitine acetyltransferase (CarAT), high-affinity choline transporter (CHT1), vesicular acetylcholine transporter (VAChT) and OCT $[53,54]$. Thus, in addition to the parasympathetic release of acetylcholine, this transmitter may have a crucial local auto-/paracrine role in regulating several aspects on the innate mucosal defense mechanisms, including mucociliary clearance, regulation of macrophage function and modulation of sensory nerves [55].

Since our findings showed that removal of the bronchial epithelium may influence the release of acetylcholine from human bronchi, we further investigated the role of indacaterol and glycopyrronium on the bronchial non-neuronal cholinergic system $[52,55,56]$. Interestingly, although indacaterol and glycopyrronium alone did not modify the release of acetylcholine from primary human bronchial epithelial cells, a combination of these drugs inhibited the epithelial release of acetylcholine with the same extent to the inhibitory effect induced by the OCT inhibitor quinine.

Taken together, these evidences allow us ruling out a direct influence of synaptic postganglionic nerve endings in the synergistic interaction between glycopyrronium and indacaterol. Nevertheless, epithelium may be at least partially responsible for the synergistic effect of glycopyrronium/indacaterol, since the drug combination was effective in reducing endogenous and non-neurogenic release of acetylcholine from bronchial epithelial cells compared with either drug administered alone. This latter evidence may explain, to some extent, the relevant synergistic interaction between glycopyrronium and indacaterol in PCLS preparations, since at the level of human bronchioles the density of vagal innervation is insignificant or even absent, thus suggesting a role of the non-neuronal cholinergic system $[57,58]$. In fact, in peripheral airways, the muscarinic $M_{3}$ receptor is expressed and may be activated by acetylcholine released from epithelial cells that may express ChAT in response to inflammatory stimuli [59].

In any case, the function of muscarinic receptors localized on human bronchial epithelium is still speculative. The activation of muscarinic $M_{1}$ may induce proliferation of isolated tracheal epithelial cells, and bronchial epithelial muscarinic $M_{3}$ receptor seems to mediate the release of 
diffusible factors, modulating contractility of underlying ASM [60]. Furthermore, the role of muscarinic $M_{2}$ receptor remains unclear in bronchial epithelium [61]. Therefore, although the nature of these factors remains unknown, we cannot exclude that muscarinic antagonists may reverse the $\mathrm{G}_{\mathrm{i}} / \mathrm{KCa}^{++}$channel inhibitory linkage induced by the activation of muscarinic $\mathrm{M}_{2}$ receptor at the level of airway epithelial cells, concurring with the similar effect elicited by $\beta_{2}$-adrenoceptor agonists through intracellular cAMP elevation and reducing the release of acetylcholine [37].

Since we have demonstrated that the synergism between a LABA and a LAMA cannot be adequately explained by the modulation of acetylcholine release, we investigated further mechanisms that might directly engage the ASM. Our data suggest that cAMP elevation induced in ASM by combining low doses of glycopyrronium plus indacaterol seems to be the main cause that explains the synergistic interaction between these bronchodilators. In fact, a noteworthy enhancement of cAMP levels was detected in human isolated bronchi treated with the glycopyrronium/indacaterol combination compared with isolated airways treated with the monocomponents. As expected, the concentrations of cAMP were not modulated by glycopyrronium, whereas indacaterol enhanced the cAMP levels by approximately three fold, independent by the presence of epithelium. On the other hand, the glycopyrronium/indacaterol combination elicited a noteworthy increase in cAMP concentrations up to approximately seven fold.

Furthermore, our results suggest that the activity of IbTX-sensitive $\mathrm{KCa}^{++}$channels is crucial for generating this significant cAMP elevation. Stimulation of the $\beta_{2^{-}}$ adrenoceptor activates the $\mathrm{KCa}^{++}$channels through both cAMP-dependent and -independent mechanisms, leading to hyperpolarisation of cell membrane and, consequently, to ASM relaxation [62,63]. To the best of our knowledge, we have demonstrated for the first time in human ASM that not only cAMP may influence the activity of $\mathrm{KCa}^{++}$channels, but also that the IbTX-sensitive $\mathrm{KCa}^{++}$channels themselves may modulate cAMP increase following the concomitant activation of the $\beta_{2^{-}}$ adrenoceptor and inhibition of muscarinic receptors.

Several pathways have been proposed to explain the intracellular cross-talk between $\beta_{2}$-adrenoceptors and muscarinic receptors at the level of the human ASM [9]. In our study, the role of IbTX-sensitive $\mathrm{KCa}^{++}$ channels seems to be predominant, since these channels may induce a direct reduction of ASM tone and, equally important, regulate the intracellular concentrations of cAMP $[64,65]$. Our data suggest that the functionality of IbTX-sensitive $\mathrm{KCa}^{++}$channels is crucial for allowing the synergistic interaction between a LABA and a LAMA, leading to a sustained and intense bronchorelaxant effect via cAMP elevation.
Since the bronchial epithelium expresses both $\beta_{2}$-adrenoceptors and muscarinic receptors [59], we also investigated whether a LABA/LAMA combination might have a role in the synthesis of cAMP in primary human bronchial epithelial cells as well. Intriguingly, glycopyrronium and indacaterol administered alone at low concentrations did not modify the basal level of cAMP, whereas the combination of these drugs increased the cAMP levels in bronchial epithelial cells. This finding suggests that the bronchial epithelium may also contribute to the modulation of cAMP levels in human bronchi following the stimulation of $\beta_{2}$-adrenoceptors and inhibition of muscarinic receptors, thus supporting the synergistic interaction elicited by the glycopyrronium/indacaterol combination.

The findings of this study prove that the synergistic interaction between glycopyrronium and indacaterol is both directly and indirectly mediated downstream by the stimulation of the cAMP-dependent pathway. In fact the block of muscarinic receptors by glycopyrronium induced synergism in the presence of cAMP stimulant agents, such as indaceterol or forskolin. On the other hand, modulating the same intracellular pathway, by combining indacaterol with forskolin, produced only an additive relaxant response.

Our effort to characterize the interaction between different bronchorelaxant agents has demonstrated that synergism may be elicited only when the pharmacological interventions are focused on specific different pathways that, unexpectedly, converge in a noteworthy downstream modulation of intracellular messengers specific for only one of the involved pathways, namely the cAMP increase induced by the activation of $\beta_{2}$-adrenoceptors. In effect, no synergistic interaction was produced by the direct activation of AC by forskolin and the concomitant stimulation of $\beta_{2}$-adrenoceptors, even in the presence of an anti-muscarinic agent.

Finally, but not less important, these findings fully corroborate the main assumption of the BI criterion, that if two or more agents act independently of one another, neither one interferes with the other, but each contributes to a common result leading to additive effect. In fact, although $\beta_{2}$-adrenoceptors agonists and anti-muscarinic agents interact with different and independent smooth muscle cell membrane receptors, they orchestrate downstream intracellular signalling pathways that interfere each other eliciting synergistic bronchorelaxant interaction [9]. Therefore, the addition of a second bronchodilator agent should be assessed considering the interference on the signalling cross-talk between different intracellular pathways.

\section{Conclusions}

In conclusion, the findings of this study suggest that coadministation of glycopyrronium and indacaterol at low 
concentrations leads to synergistic improvement of bronchodilation in both medium and small airways, when compared with either drug administered alone, due to a significant increase in cAMP concentrations at the level of both ASM and bronchial epithelial cells and a decrease in the release of acetylcholine from the epithelium.

\section{Abbreviations}

$\mathrm{Bl}$, Bliss Independence; CRC, concentration response curve; CAMP, cyclic adenosine monophosphate; $\mathrm{E}$, effect; $\mathrm{EC}$, effective dose concentration; $E C_{n}$, dose concentration inducing $n \%$ maximal effect; EFS, electrical field stimulation; $E_{\max }$ maximal effect; FSK, forskolin; IbTX, iberiotoxin; $\mathrm{KCa}^{++}$ channels, calcium activated potassium channels; NVA237, glycopyrronium bromide; OCT, organic cation transporter; PCLS, precision cut lung slice; pEC 50 , - LogEC $_{50}$; QAB149, indacaterol fumarate; TeTX, tetanus toxin.

\section{Acknowledgments}

NA

\section{Authors' contributions}

MC: designed the research study, contributed essentially reagents and tools, wrote the manuscript. LC: conducted experiments, acquired data, designed the research study, wrote the manuscript. EP: wrote the manuscript. JO: wrote the manuscript. FF: conducted experiments. PR: contributed essentially reagents and tools, wrote the manuscript. MGM: designed the research study, wrote the manuscript. All authors read and approved the final manuscript.

\section{Competing interests}

Mario Cazzola acted as a consultant for Novartis.

Luigino Calzetta has been supported by a research grant partially funded by Novartis.

Paola Rogliani was a member of the Speaker Bureau for Novartis. Maria Gabriella Matera received funding for research from Novartis, Ermanno Puxeddu, Josuel Ora and Francesco Facciolo declare that they have no competing interests.

\section{Author details}

${ }^{1}$ Department of Systems Medicine, Chair of Respiratory Medicine, University of Rome Tor Vergata, Rome, Italy. ${ }^{2}$ Department of Systems Medicine, Respiratory Pharmacology Research Unit, University of Rome Tor Vergata, Via Montpellier 1, 00133 Rome, Italy. ${ }^{3}$ Division of Respiratory Medicine, University Hospital Tor Vergata, Rome, Italy. ${ }^{4}$ Regina Elena National Cancer Institute, Thoracic Surgery Unit, Rome, Italy. ${ }^{5}$ Department of Experimental Medicine, Unit of Pharmacology, Second University of Naples, Naples, Italy.

\section{Received: 4 March 2016 Accepted: 3 June 2016}

\section{Published online: 13 June 2016}

\section{References}

1. van der Molen T, Cazzola M. Beyond lung function in COPD management: effectiveness of LABA/LAMA combination therapy on patient-centred outcomes. Prim Care Respir J. 2012;21(1):101-8. doi:10.4104/pcrj.2011.00102.

2. Cazzola M, Matera MG. Bronchodilators: current and future. Clin Chest Med. 2014;35(1):191-201. doi:10.1016/j.ccm.2013.10.005.

3. Bateman ED, Ferguson GT, Barnes N, Gallagher N, Green Y, Henley M, et al. Dual bronchodilation with QVA149 versus single bronchodilator therapy: the SHINE study. Eur Respir J. 2013;42(6):1484-94. doi:10.1183/09031936.00200212.

4. Wedzicha JA, Decramer M, Ficker JH, Niewoehner DE, Sandstrom T, Taylor AF, et al. Analysis of chronic obstructive pulmonary disease exacerbations with the dual bronchodilator QVA149 compared with glycopyrronium and tiotropium (SPARK): a randomised, double-blind, parallel-group study. Lancet Respir Med. 2013;1(3):199-209. doi:10.1016/S2213-2600(13)70052-3.

5. Matera MG, Rogliani P, Rinaldi B, Cazzola M. Umeclidinium bromide + vilanterol for the treatment of chronic obstructive pulmonary disease. Expert Rev Clin Pharmacol. 2015;8(1):35-41. doi:10.1586/17512433.2015.977256.

6. Cazzola M, Calzetta L, Page CP, Rogliani P, Facciolo F, Gavalda A, et al. Pharmacological characterization of the interaction between aclidinium bromide and formoterol fumarate on human isolated bronchi. Eur Pharmacol. 2014:745:135-43. doi:10.1016/j.ejphar.2014.10.025.

7. Cazzola M, Calzetta L, Segreti A, Facciolo F, Rogliani P, Matera MG. Translational Study Searching for Synergy between Glycopyrronium and Indacaterol. COPD. 2015;12(2):175-81. doi:10.3109/15412555.2014.922172.

8. Cazzola M, Calzetta L, Ora J, Puxeddu E, Rogliani P, Matera MG. Searching for the synergistic effect between aclidinium and formoterol: From bench to bedside. doi: 10.1016/j.rmed.2015.08.005. Respir Med. 2015. doi:10.1016/j.rmed.2015.08.005

9. Calzetta L, Matera MG, Cazzola M. Pharmacological interaction between LABAs and LAMAs in the airways: optimizing synergy. Eur J Pharmacol. 2015;761:168-73. doi:10.1016/j.ejphar.2015.05.020.

10. Pelaia G, Maselli R, Matera MG. Treatment of Chronic Obstructive Pulmonary Disease by Dual Bronchodilation with Coformulation of Indacaterol/ Glycopyrronium. Pharmacology. 2014;94(5-6):249-58. doi:10.1159/000368986.

11. Panettieri Jr RA. Bronchodilators, receptors and cross-talk: together is better? DOl: 10.1080/00325481.2015.1080589. Postgrad Med. 2015(ahead-of-print):1-10.

12. Calzetta L, Spina D, Cazzola M, Page CP, Facciolo F, Rendina EA, et al. Pharmacological Characterization of Adenosine Receptors on Isolated Human Bronchi. Am J Respir Cell Mol Biol. 2011. doi:10.1165/rcmb.2011-00560C.

13. Cazzola M, Calzetta L, Page CP, Rinaldi B, Capuano A, Matera MG. Protein prenylation contributes to the effects of LPS on EFS-induced responses in human isolated bronchi. Am J Respir Cell Mol Biol. 2011:45(4):704-10. doi:10.1165/rcmb.2010-03060C.

14. Matera MG, Calzetta L, Passeri D, Facciolo F, Rendina EA, Page C, et al. Epithelium integrity is crucial for the relaxant activity of brain natriuretic peptide in human isolated bronchi. Br J Pharmacol. 2011;163(8):1740-54. doi:10.1111/j.1476-5381.2011.01339.x.

15. Calzetta L, Cazzola M, Page CP, Rogliani P, Facciolo F, Matera MG. Pharmacological characterization of the interaction between the dual phosphodiesterase (PDE) 3/4 inhibitor RPL554 and glycopyrronium on human isolated bronchi and small airways. Pulm Pharmacol Ther. 2015;32:15-23. doi:10.1016/j.pupt.2015.03.007.

16. Fulcher ML, Gabriel S, Burns KA, Yankaskas JR, Randell SH. Well-differentiated human airway epithelial cell cultures. Methods Mol Med. 2005;107:183-206. doi:1-59259-861-7:183

17. Rogliani P, Calzetta L, Rendina EA, Massullo D, Dauri M, Rinaldi B, et al. The influence of propofol, remifentanil and lidocaine on the tone of human bronchial smooth muscle. Pulm Pharmacol Ther. 2013;26(3):325-31. doi:10.1016/j.pupt.2013.01.002.

18. Abramoff MD, Magalhaes PJ, Ram SJ. Image processing with ImageJ. Biophoton Int. 2004;11(7):1081-8693.

19. Matera MG, Calzetta L, Rogliani P, Bardaro F, Page CP, Cazzola M Evaluation of the effects of the R- and S-enantiomers of salbutamol on equine isolated bronchi. Pulm Pharmacol Ther. 2011;24(2):221-6. doi:10.1016/j. pupt.2010.12.008.

20. Matera MG, Calzetta L, Parascandolo V, Curradi G, Rogliani P, Cazzola M. Relaxant effect of brain natriuretic peptide in nonsensitized and passively sensitized isolated human bronchi. Pulm Pharmacol Ther. 2009:22(6):478-82. doi:S1094-5539(09)00052-2

21. Binks AP, Paydarfar D, Schachter SC, Guz A, Banzett RB. High strength stimulation of the vagus nerve in awake humans: a lack of cardiorespiratory effects. Respir Physiol. 2001:127(2-3):125-33. doi:S0034568701002523.

22. Holland M, Langton PD, Standen NB, Boyle JP. Effects of the BKCa channel activator, NS1619, on rat cerebral artery smooth muscle. Br J Pharmacol. 1996;117(1):119-29.

23. Bialecki RA, Stinson-Fisher C. KCa channel antagonists reduce NO donormediated relaxation of vascular and tracheal smooth muscle. Am J Physiol. 1995;268(1 Pt 1):L152-9.

24. Brayden JE, Nelson MT. Regulation of arterial tone by activation of calciumdependent potassium channels. Science. 1992;256(5056):532-5.

25. Corompt E, Bessard G, Lantuejoul S, Naline E, Advenier C, Devillier P. Inhibitory effects of large Ca2 + -activated $\mathrm{K}+$ channel blockers on beta-adrenergic- and NO-donor-mediated relaxations of human and guinea-pig airway smooth muscles. Naunyn Schmiedebergs Arch Pharmacol. 1998;357(1):77-86.

26. Link E, Edelmann L, Chou JH, Binz T, Yamasaki S, Eisel U, et al. Tetanus toxin action: inhibition of neurotransmitter release linked to synaptobrevin proteolysis. Biochem Biophys Res Commun. 1992;189(2):1017-23.

27. Pierce EJ, Davison MD, Parton RG, Habig WH, Critchley DR. Characterization of tetanus toxin binding to rat brain membranes. Evidence for a highaffinity proteinase-sensitive receptor. Biochem J. 1986;236(3):845-52. 
28. Rabasseda X, Blasi J, Marsal J, Dunant Y, Casanova A, Bizzini B. Tetanus and botulinum toxins block the release of acetylcholine from slices of rat striatum and from the isolated electric organ of Torpedo at different concentrations. Toxicon. 1988;26(4):329-36.

29. Mochida S, Poulain B, Weller U, Habermann E, Tauc L. Light chain of tetanus toxin intracellularly inhibits acetylcholine release at neuro-neuronal synapses, and its internalization is mediated by heavy chain. FEBS Lett. 1989; 253(1-2):47-51.

30. Naline E, Bardou M, Devillier P, Molimard M, Dumas M, Chalon P, et al. Inhibition by SR 59119A of isoprenaline-, forskolin- and VIP-induced relaxation of human isolated bronchi. Pulm Pharmacol Ther. 2000;13(4):167-74. doi:10.1006/pupt.2000.0246.S1094-5539(00)90246-3.

31. Motulsky H, Christopoulos A. Fitting models to biological data using linear and nonlinear regression : a practical guide to curve fitting. Oxford: Oxford University Press; 2004.

32. Rogliani P, Calzetta L, Ora J, Lipsi R, Segreti A, Matera MG, et al. Pharmacological assessment of the onset of action of aclidinium and glycopyrronium versus tiotropium in COPD patients and human isolated bronchi. Eur J Pharmacol. 2015. doi:10.1016/j.ejphar.2015.04.042.

33. Calzetta L, Page CP, Spina D, Cazzola M, Rogliani P, Facciolo F, et al. Effect of the mixed phosphodiesterase 3/4 inhibitor RPL554 on human isolated bronchial smooth muscle tone. J Pharmacol Exp Ther. 2013;346(3):414-23. doi:10.1124/jpet.113.204644.

34. European Medicines Agency. EMEA/H/C/003755/0000. Available at http://www.ema.europa.eu/docs/en_GB/document_library/EPAR_Public_assessment_report/human/003755/WC500151413.pdf. Accessed April 5, 2016. 2013.

35. US Food and Drug Administration. Utibron Neohaler safely and effectively. Available at http://www.accessdata.fda.gov/drugsatfda_docs/label/2015/ 207930s000lbl.pdf. Accessed April 5, 2016. 2015.

36. Calzetta L, Rogliani P, Matera MG, Cazzola M. A systematic review with meta-analysis of dual bronchodilation with LAMA/LABA for the treatment of stable chronic obstructive pulmonary disease. Chest. 2016. doi:10.1016/j. chest.2016.02.646.

37. Kume H, Fukunaga K, Oguma T. Research and development of bronchodilators for asthma and COPD with a focus on $\mathrm{G}$ protein/KCa channel linkage and beta2-adrenergic intrinsic efficacy. Pharmacol Ther. 2015;156:75-89. doi:10.1016/j.pharmthera.2015.09.004

38. Billington CK, Penn RB. Signaling and regulation of $G$ protein-coupled receptors in airway smooth muscle. Respir Res. 2003:4:2.

39. Shore S, Irvin CG, Shenkier T, Martin JG. Mechanisms of histamine-induced contraction of canine airway smooth muscle. J Appl Physiol Respir Environ Exerc Physiol. 1983;55(1 Pt 1):22-6.

40. Aizawa $\mathrm{H}$, Inoue $\mathrm{H}$, Miyazaki N, Hara N. Histamine-induced increase in isometric tension of smooth muscle is mediated by local vagus nerve in human bronchus. Respiration. 2000;67(6):652-6. doi:56295.

41. Cazzola M, Calzetta L, Rogliani P, Puxeddu E, Facciolo F, Matera MG. Interaction between corticosteroids and muscarinic antagonists in human airways. Pulm Pharmacol Ther. 2016:36:1-9.

42. Smit M, Zuidhof AB, Bos IST, Maarsingh H, Gosens R, Zaagsma J, et al. The bronchoprotective effect of olodaterol against histamine is synergistically enhanced and prolonged by tiotropium bromide. Am J Respir Crit Care Med. 2011;183:A1379.

43. Smit M, Zuidhof AB, Bos SIT, Maarsingh H, Gosens R, Zaagsma J, et al. Bronchoprotection by olodaterol is synergistically enhanced by tiotropium in a guinea pig model of allergic asthma. J Pharmacol Exp Ther. 2014;348(2):303-10.

44. Chandrasekera PC, Pippin JJ. The human subject: an integrative animal model for 21(st) century heart failure research. Am J Transl Res. 2015;7(9):1636-47.

45. Belvisi MG, Patel HJ, Takahashi T, Barnes PJ, Giembycz MA. Paradoxical facilitation of acetylcholine release from parasympathetic nerves innervating guinea-pig trachea by isoprenaline. Br J Pharmacol. 1996;117(7):1413-20.

46. Matera MG, Rogliani P, Cazzola M. Muscarinic receptor antagonists for the treatment of chronic obstructive pulmonary disease. Expert Opin Pharmacother. 2014;15(7):961-77. doi:10.1517/14656566.2014.899581.

47. Alagha K, Palot A, Sofalvi T, Pahus L, Gouitaa M, Tummino C, et al. Longacting muscarinic receptor antagonists for the treatment of chronic airway diseases. Ther Adv Chronic Dis. 2014;5(2):85-98. doi:10.1177/2040622313518227.

48. Haddad EB, Patel H, Keeling JE, Yacoub MH, Barnes PJ, Belvisi MG. Pharmacological characterization of the muscarinic receptor antagonist, glycopyrrolate, in human and guinea-pig airways. Br J Pharmacol. 1999; 127(2):413-20. doi:10.1038/sj.bjp.0702573.
49. Barnes PJ. Muscarinic receptor subtypes in airways. Eur Respir J. 1993;6(3):328-31.

50. Watson N, Barnes PJ, Maclagan J. Actions of methoctramine, a muscarinic M2 receptor antagonist, on muscarinic and nicotinic cholinoceptors in guinea-pig airways in vivo and in vitro. Br J Pharmacol. 1992;105(1):107-12.

51. Kajekar R, Rohde HK, Myers AC. The integrative membrane properties of human bronchial parasympathetic Ganglia neurons. Am J Respir Crit Care Med. 2001;164(10 Pt 1):1927-32.

52. Wessler I, Kirkpatrick CJ. Acetylcholine beyond neurons: the non-neuronal cholinergic system in humans. Br J Pharmacol. 2008;154(8):1558-71. doi:10.1038/bjp.2008.185.

53. Wessler I, Kilbinger H, Bittinger F, Unger R, Kirkpatrick CJ. The non-neuronal cholinergic system in humans: expression, function and pathophysiology. Life Sci. 2003;72(18-19):2055-61. doi:S0024320503000833.

54. Reinheimer T, Bernedo P, Klapproth H, Oelert H, Zeiske B, Racke K, et al. Acetylcholine in isolated airways of rat, guinea pig, and human: species differences in role of airway mucosa. Am J Physiol. 1996;270(5 Pt 1):L722-8.

55. Kummer W, Lips KS, Pfeil U. The epithelial cholinergic system of the airways. Histochem Cell Biol. 2008;130(2):219-34. doi:10.1007/s00418-008-0455-2.

56. Wessler IK, Kirkpatrick CJ. The Non-neuronal cholinergic system: an emerging drug target in the airways. Pulm Pharmacol Ther. 2001;14(6):423-34. doi:10.1006/pupt.2001.0313.

57. Belvisi MG. Overview of the innervation of the lung. Curr Opin Pharmacol. 2002;2(3):211-5. doi:S1471489202001455.

58. Canning BJ, Fischer A. Neural regulation of airway smooth muscle tone. Respir Physiol. 2001;125(1-2):113-27. doi:S0034568700002085.

59. Barnes PJ. Distribution of receptor targets in the lung. Proc Am Thorac Soc. 2004;1(4):345-51. doi:10.1513/pats.200409-045MS.

60. Eglen RM. Muscarinic receptor subtypes in neuronal and non-neuronal cholinergic function. Auton Autacoid Pharmacol. 2006;26(3):219-33. doi:10.1111/j.1474-8673.2006.00368.x.

61. Koyama S, Rennard SI, Robbins RA. Acetylcholine stimulates bronchial epithelial cells to release neutrophil and monocyte chemotactic activity. Am J Physiol. 1992;262(4 Pt 1):L466-71.

62. Kume H, Graziano MP, Kotlikoff MI. Stimulatory and inhibitory regulation of calcium-activated potassium channels by guanine nucleotide-binding proteins. Proc Natl Acad Sci U S A. 1992;89(22):11051-5.

63. Laurent F, Michel A, Bonnet PA, Chapat JP, Boucard M. Evaluation of the relaxant effects of SCA40, a novel charybdotoxin-sensitive potassium channel opener, in guinea-pig isolated trachealis. Br J Pharmacol. 1993;108(3):622-6.

64. Snetkov VA, Hirst SJ, Twort CH, Ward JP. Potassium currents in human freshly isolated bronchial smooth muscle cells. Br J Pharmacol. 1995;115(6):1117-25.

65. Morin C, Sirois M, Echave V, Gomes MM, Rousseau E. Functional effects of 20-HETE on human bronchi: hyperpolarization and relaxation due to BKCa channel activation. Am J Physiol Lung Cell Mol Physiol. 2007;293(4):L1037-44. doi:10.1152/ajplung.00145.2007.

\section{Submit your next manuscript to BioMed Central and we will help you at every step:}

- We accept pre-submission inquiries

- Our selector tool helps you to find the most relevant journal

- We provide round the clock customer support

- Convenient online submission

- Thorough peer review

- Inclusion in PubMed and all major indexing services

- Maximum visibility for your research

Submit your manuscript at www.biomedcentral.com/submit 